\title{
Precipitation in Iran from 2003 to 2021
}

\author{
Omid Memarian Sorkhabi \\ (omidmemaryan@gmail.com) \\ Department of Geomatics Engineering, Faculty of Civil Engineering and Transportation, University of Isfahan, \\ Isfahan, Iran.
}

\begin{abstract}
Satellite data between 2003 and 2021 have been used for Iran's precipitation. The average monthly precipitation is about $20 \mathrm{~mm}$. The maximum amount of monthly precipitation is observed in 2019 . The average is $233 \mathrm{~mm}$. The lowest precipitation years in Iran are 2009, 2019 and 2018, respectively, and the highest precipitation is in 2020, 2007 and 2005, respectively.
\end{abstract}

Keywords: Precipitation, Iran, 2020, Precipitation measurement

\section{Introduction}

According to official statistics, the amount of rain evaporation in Iran is about 2700 $\mathrm{mm}$ and the global average is over $800 \mathrm{~mm}$. Therefore, we have one-third of global precipitation and three times the global evaporation in Iran, which indicates the importance of protecting water resources [1].

The air temperature in Iran is also higher than normal and this situation causes snow storage and runoff to be drastically reduced, especially in the Zagros Basin. As a result, the discharge of rivers in the warm season will be much lower than normal, which raises concerns in the field of agriculture and even water supply in rural and urban areas [2]. Geodesy and satellite data can play a good role in measuring climatic parameters [3-11].

In this study, precipitation in Iran from 2003 to 2021 has been studied. 


\section{Results}

Satellite data between 2003 and 2021 have been used for Iran's precipitation data, as shown in Figure 1. The average monthly precipitation is about $20 \mathrm{~mm}$. The maximum amount of monthly precipitation is observed in 2019.

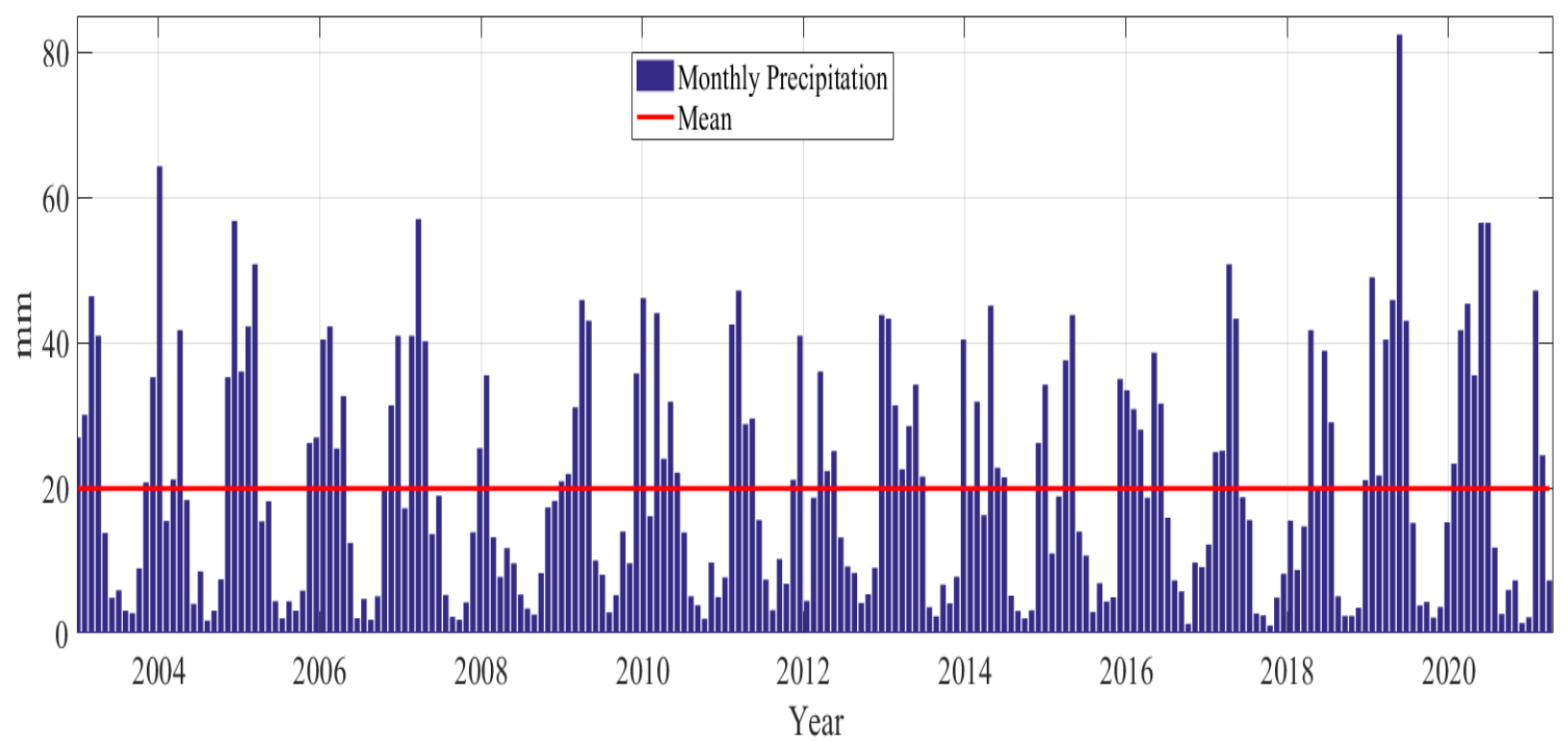

Figure 1 Precipitation in Iran from 2003-2021

The average precipitation in Iran is $233 \mathrm{~mm}$. Figure 2 shows the average precipitation in Iran from 2003-2021. 2009 is calculated as the least rainy year and 2020 as the rainiest year. 


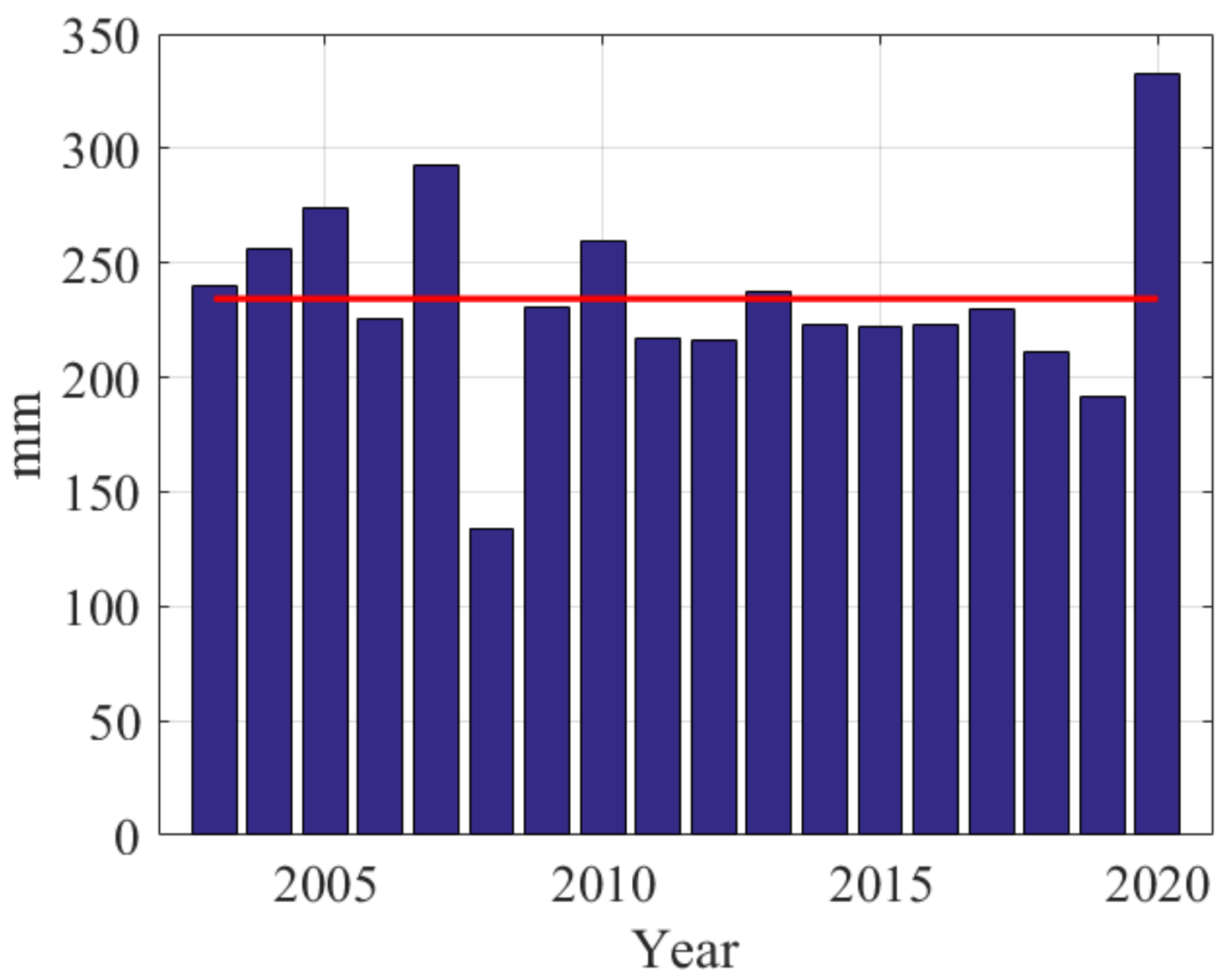

Figure 2 Average precipitation in Iran from 2003-2020

\section{Conclusion}

Satellite data between 2003 and 2021 have been used for Iran's precipitation data. The average monthly precipitation is about $20 \mathrm{~mm}$. The maximum amount of monthly precipitation is observed in 2019. The average precipitation in Iran is 233 $\mathrm{mm}$. The lowest precipitation years in Iran are 2009, 2019 and 2018, respectively, and the highest precipitation is in 2020, 2007 and 2005, respectively. 


\section{Competing interests:}

The authors declare no competing interests.

\section{References}

[1] Moghanlo S, Alavinejad M, Oskoei V, Saleh HN, Mohammadi AA, Mohammadi H, DerakhshanNejad Z. Using artificial neural networks to model the impacts of climate change on dust phenomenon in the Zanjan region, north-west Iran. Urban Climate. 2021 Jan 1;35:100750.

[2] Doulabian S, Golian S, Toosi AS, Murphy C. Evaluating the effects of climate change on precipitation and temperature for Iran using RCP scenarios. Journal of Water and Climate Change. $2021 \mathrm{Feb}$;2(1):166-84.

[3] Memarian Sorkhabi O, Asgari J, Amiri-Simkooei A. Wavelet decomposition and deep learning of altimetry waveform retracking for Lake Urmia water level survey. Marine Georesources \& Geotechnology. 2021 Mar 10:1-1

[4] Memarian Sorkhabi O. Geoid determination based on log sigmoid function of artificial neural networks:(a case study: Iran). Journal of Artificial Intelligence in Electrical Engineering. 2015 Mar 1;3(12):18-24.

[5] Sorkhabia OM, DJAMOUR Y. Wavelet Transform Analysis of Ionospheric Electron Content Changes before Large Earthquakes. Journal of Geomatics Science and Technology, 2015.

[6] Sorkhabi OM, Naderi A, Emadi R. Terrain Effect on Geoid Determination Case Study: NW Iran. Journal of Geomatics Science and Technology. 2014 Nov 10;4(2):139-48.

[7] Sorkhabi OM. Deep learning of dynamic sea-level variability to investigate the relationship with the floods in Gothenburg. 2021. DOI: 10.21203/rs.3.rs-422515/v1

[8] Memarian Sorkhabi O, Asgari J, Amiri-Simkooei A. Monitoring of Caspian Sea-level changes using deep learning-based 3D reconstruction of GRACE signal. Measurement. 2021 Apr 1;174:109004.

[9] Sorkhabia OM, Asgaria J, Amiri-Simkooeia A. Caspian Sea Level Survey with GRACE and GRACE-FO. 2020.

[10] Memarian Sorkhabi O, Djamour Y. Estimation of Geodetic Virtual Velocity Based On Back Propagation Artificial Neural Networks (Case Study: NW Iran). Journal of Geoscience. 2015 Jun 1;24(95):69-76.

[11] Memarian Sorkhabi O, Asgari J, Amiri Simkooei A. Analysis of Greenland mass changes based on GRACE four-dimensional wavelet decomposition. Remote Sensing Letters. 2021 May 4;12(5):499-509. 